\title{
Isolation, Complementation and Partial Characterization of Mutants of the Methanol Autotroph Xanthobacter H4-14 Defective in Methanol Dissimilation
}

\author{
By CRAIG A. WEAVER† AND MARY E. LIDSTROM* $\ddagger$ \\ Department of Microbiology, SC-42, University of Washington, Seattle, WA 98195, USA
}

(Received 18 November 1986; revised 6 February 1987)

\begin{abstract}
Seven mutants of Xanthobacter H4-14, unable to grow on methanol but capable of growth on formate, were isolated and complemented with a chromosomal clone bank constructed in the broad-host-range cosmid pVK100. One mutant could not be complemented but the others fell into four distinct complementation groups that involved three different recombinant clones. All of the complementing regions were separated by at least $10 \mathrm{kbp}$. The five complementation classes had different phenotypic characteristics and were defective in different aspects of methanol and formaldehyde oxidation. Class I mutants were defective in methanol oxidation, class II mutants were impaired in formaldehyde oxidation, class III mutants appeared to be defective in a regulatory element involving the methanol oxidation system, and class IV mutants appeared to be defective in a regulatory element involving formaldehyde oxidation. Class $\mathrm{V}$ mutants exhibited a methanol-sensitive phenotype, which was correlated with an imbalance between methanol and formaldehyde dehydrogenase activities. Analysis of this class suggested it was defective in a repressor that regulated methanol dissimilation functions.
\end{abstract}

\section{INTRODUCTION}

Methylotrophic micro-organisms have received considerable attention due to their potential usefulness in industry and because of their unique position in nature (Allen et al., 1984; Haber et al., 1983; Higgins et al., 1980; Windass et al., 1980). The study of methylotrophic growth has recently benefited from the application of genetics and recombinant DNA techniques (Holloway, 1984), which have made possible the study of gene order and molecular mechanisms of regulation in a variety of strains.

Most methylotrophic bacteria grow on $\mathrm{C}_{1}$ compounds by oxidizing them to $\mathrm{CO}_{2}$ and incorporating carbon at the level of formaldehyde (Anthony, 1982). However, one group of methylotrophic bacteria grows autotrophically on methanol after its stepwise oxidation to $\mathrm{CO}_{2}$ (Anthony, 1982; Fig. 1). We have studied one such 'methanol autotroph', Xanthobacter sp. strain H4-14 (Lidstrom-O'Connor et al., 1983; Lehmicke \& Lidstrom, 1985; Weaver \& Lidstrom, 1985). This bacterium contains methanol dehydrogenase $(\mathrm{MeDH})$ and formate dehydrogenase (FDH) activities typical of other methylotrophic bacteria (Weaver \& Lidstrom, 1985). However, the formaldehyde dehydrogenase (FADH) was less clearly identified. The most likely candidate was a dye-linked FADH activity that could not be detected spectrophotometrically, but was detectable by activity stains of non-denaturing polyacrylamide gels. MeDH and FDH were induced (or de-repressed) by methanol, but the regulation of the dye-linked FADH was more

† Present address: Synergen Inc., 1885 33rd Street, Boulder, CO 80301, USA.

$\ddagger$ Present address: Environmental Engineering Science Keck Laboratory, 138-78 California Institute of Technology, Pasadena, CA 91125, USA.

Abbreviations: MeDH, methanol dehydrogenase; FDH, formate dehydrogenase; FADH, formaldehyde dehydrogenase; $\mathrm{Tc}^{r}$, tetracycline-resistant. 


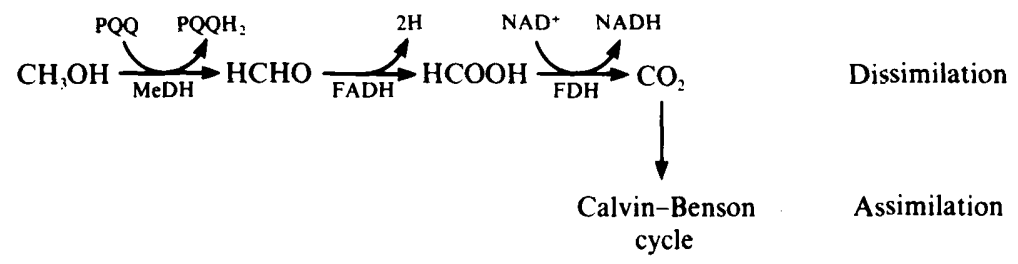

Fig. 1. Growth of Xanthobacter H4-14 on $\mathrm{C}_{1}$ compounds.

complex. This activity decreased during the lag phase in induction curves, but increased concomitantly with the MeDH and FDH later in the growth cycle. Two methanol-inducible polypeptides, approximately 10 and $22 \mathrm{kDa}$ in size, were also detected. Their identity remains unknown but, by analogy with other methylotrophs, it is possible that they represent $c$-type cytochromes specifically involved in methanol dissimilation (Beardmore-Gray et al., 1982; O'Keefe \& Anthony, 1980). The MeDH activity and synthesis of the $10 \mathrm{kDa}$ polypeptide appeared to be coordinately regulated.

We now report the isolation of Xanthobacter H4-14 mutants defective in methanol dissimilation $\left(\mathrm{Moh}^{-}\right)$and the complementation of these mutants using a chromosomal clone bank constructed with DNA from the parental wild-type strain. Analysis of these mutants suggests that methanol dissimilation is regulated by a repressor mechanism in Xanthobacter H4-14.

\section{METHODS}

Strains, plasmids and growth conditions. The bacterial strains, plasmids, and source of transposon $\operatorname{Tn} 5$ are listed in Table 1. The minimal and complex growth media for Xanthobacter H4-14 were described by LidstromO'Connor et al. (1983) and Weaver \& Lidstrom (1985). Escherichia coli strains were grown and maintained in LB medium (Miller, 1972). The following antibiotic concentrations were used where appropriate: tetracycline. $\mathrm{HCl}$, $10 \mu \mathrm{g} \mathrm{ml}^{-1}$; kanamycin sulphate, $50 \mu \mathrm{g} \mathrm{ml}^{-1}$; nalidixic acid, $20 \mu \mathrm{g} \mathrm{ml}^{-1}$.

Mutagenesis and enrichment. Mutagenesis of Xanthobacter H4-14 was done as described by Miller (1972). Cell densities of approximately $10^{8} \mathrm{ml}^{-1}$ were used. Cells were exposed to $1.5 \%(\mathrm{v} / \mathrm{v})$ ethyl methanesulphonate for $120 \mathrm{~min}$ at $30^{\circ} \mathrm{C}$, or $1.0 \mathrm{mg}$ nitrous acid $\mathrm{ml}^{-1}$ for $30 \mathrm{~min}$ at $30^{\circ} \mathrm{C}, \mathrm{pH} 4.6$. These conditions resulted in approximately $99 \%$ killing. Survivors were subjected to two cycles of enrichment with $2 \%(\mathrm{w} / \mathrm{v})$ glycine in the

Table 1. Bacteria, plasmids and phage used in this study

str $^{r}$, Streptomycin-resistant; Moh ${ }^{+}$, methanol-positive; recA, recombination-deficient; polA, DNApolymerase-I-deficient; $g y r A$, nalidixic acid-resistant; lac Z m15, $\beta$-galactosidase deletion; IncP1, incompatibility group $\mathrm{P} 1$; $r l x$, mobilization-positive; tra, conjugation-positive; rex, prophagedefective.

\begin{tabular}{|c|c|c|}
\hline & Relevant characteristics & Source or reference \\
\hline Xanthobacter H4-14 & $\operatorname{str}^{r} \mathrm{Moh}^{+}$ & Lehmicke \& Lidstrom (1985) \\
\hline $\begin{array}{l}\text { E. coli } \\
\text { HB101 } \\
\text { SF800 } \\
\text { MM294 } \\
\text { JM83 }\end{array}$ & 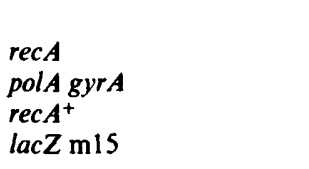 & $\begin{array}{l}\text { Maniatis et al. (1982) } \\
\text { Delucia \& Cairns (1969) } \\
\text { Backman et al. (1967) } \\
\text { Messing (1979) }\end{array}$ \\
\hline $\begin{array}{l}\text { Plasmids } \\
\text { pVK 100 } \\
\text { pRK404 } \\
\text { pRK 2013 }\end{array}$ & 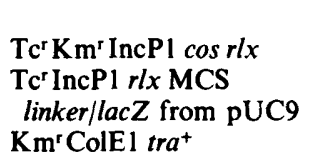 & $\begin{array}{l}\text { Knauf \& Nester (1982) } \\
\text { Ditta et al. (1985) } \\
\text { Figurski \& Helinski (1979) }\end{array}$ \\
\hline $\begin{array}{l}\text { Phage } \\
\lambda:: \operatorname{Tn} 5\end{array}$ & $\begin{array}{l}\text { Defective lambda } \\
\text { rex::Tn } 5\end{array}$ & Ruvkun \& Ausubel (1981) \\
\hline
\end{tabular}


presence of methanol ( $16 \mathrm{~h}$ with methanol alone followed by incubation with methanol + glycine for $8 \mathrm{~h})$. Glycine kills growing cells of Xanthobacter H4-14, and therefore its presence allows enrichment for non-growing (mutant) cells. Survivors were recovered in nutrient broth and individuals were screened for growth on methanol.

Transposon mutagenesis of recombinant plasmids in E. coli JM83 was as described by Weaver et al. (1981).

Clone bank construction. Chromosomal DNA from Xanthobacter H4-14 was prepared and inserted into the HindIII site in the $\mathrm{Km}^{\mathrm{r}}$ gene of the broad-host-range cosmid vector pVK 100 (Knauf \& Nester, 1982) as described by Fulton et al. (1984). Average insert size was about $20 \mathrm{kbp}$ and more than $90 \%$ of the clones contained inserts. The clone bank was stored as a pool of tetracycline-resistant $E$. coli $\mathrm{HB} 101$ transfectants.

DNA manipulation. Small- and large-scale plasmid isolations, restrictions, ligations and agarose gel electrophoresis were done as described by Maniatis et al. (1982) or as recommended by the enzyme supplier.

Plasmid mobilization and complementation of mutants. Mobilization of plasmids between $E$. coli and Xanthobacter strains involved triparental filter matings with approximately equal numbers of donor, recipient and mobilizer $(E$. coli MM294 containing pRK2013). Matings were incubated overnight at $30^{\circ} \mathrm{C}$ followed by suspension, dilution and plating. Xanthobacter strains that had received a plasmid (pVK100, pRK404 or a recombinant version thereof) were selected on minimal medium with citrate and tetracycline. E. coli SF800 (polA) cells that had received a broad-host-range plasmid from Xanthobacter strains were selected on LB medium containing tetracycline; Xanthobacter H4-14 does not grow on LB medium. For initial complementation of the $\mathrm{Moh}^{-}$mutants, the pooled clone bank was mated with individual mutants and the mating mixture was screened for Xanthobacter cells that were able to grow on minimal medium plates containing methanol. To confirm complementation, the complementing clone was transferred from the Xanthobacter mutant into $E$. coli by a triparental filter mating and transferred back into the appropriate Xanthobacter mutant with selection on plates containing citrate and tetracycline. The transconjugants were then tested for growth on methanol plates.

Enzyme and protein analysis. Crude extracts were prepared and assayed for MeDH, FADH and polypeptide patterns as described by Johnson \& Quayle (1964) and Weaver \& Lidstrom (1985). The assays involved the standard dichlorophenolindophenol/phenazine methosulphate linked assay for MeDH and activity stains on nondenaturing polyacrylamide gels for the putative $C_{1}$ FADH.

Formaldehyde accumulation assay. Cells were grown on minimal medium with citrate $\left(0.1 \%\right.$, w/v) to an $O_{600}$ of 0.7 , harvested, washed in cold medium, and resuspended in cold medium lacking substrate. Methanol oxidase activity was estimated by measuring methanol-dependent $\mathrm{O}_{2}$ uptake in a Rank oxygen electrode. Formaldehyde accumulation was measured by adding methanol to the rest of the cell suspension to a final concentration of $0.07 \%$ (w/v) and assaying samples at various times by the method of Nash (1953). Controls contained no cells and no methanol.

\section{RESULTS AND DISCUSSION}

\section{Isolation of $\mathrm{Moh}^{-}$mutants}

Derivatives of Xanthobacter H4-14 str $^{\mathrm{r}}$ defective in growth on minimal medium with methanol as the carbon and energy source were obtained after treatment with ethyl methanesulphonate or nitrous acid and subsequent glycine enrichment (see Methods). Such mutants were obtained at a frequency of approximately $0.2-0.5 \%$ of viable cells after two rounds of enrichment. This seemingly low frequency was presumably due to the oligotrophic nature of this strain, which allows it to scavenge low-level nutrients from agar plates. About one-half of the mutants isolated were auxotrophs. The remainder were stable mutants unable to grow in liquid medium on methanol but fully capable of growth on citrate, succinate, glycerol or nutrient broth. Several of these mutants were apparently defective in autotrophic $\mathrm{CO}_{2}$ fixation as they were unable to grow chemolithotrophically on $\mathrm{H}_{2} / \mathrm{CO}_{2}$. The characterization and complementation of this mutant class were described by Lehmicke \& Lidstrom (1985). The isolates able to grow on $\mathrm{H}_{2} / \mathrm{CO}_{2}$ but unable to grow on methanol (FNB27, MC44, MA47, MEH19, FNA3, MEJ32 and MNE22) were assumed to be specifically defective in methanol dissimilation $\left(\mathrm{Moh}^{-}\right)$and were used for further study.

\section{Complementation of the $\mathrm{Moh}^{-}$mutants}

In order to place the mutants into genetic complementation classes, each was mated with a pooled Xanthobacter H4-14 clone bank constructed in the broad-host-range vector pVK100 using a partial HindIII digest of total genomic DNA. Tetracycline-resistant ( $\mathrm{Tc}^{\mathrm{r}}$ ) Xanthobacter cells that were capable of growth on methanol were selected for. Complementation of FNB27, 


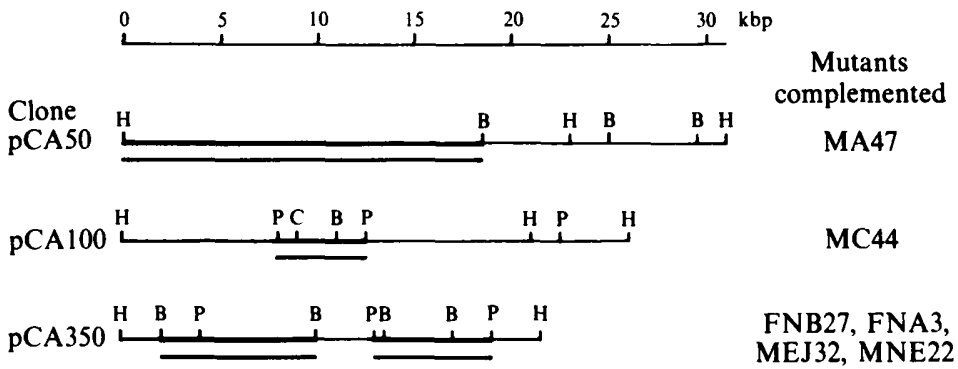

Fig. 2. DNA fragments that complement Moh- mutants. H, HindIII; B, BamHI; P, PstI; C, ClaI. Complementing subclones are underlined below each clone. See Fig. 3 for details of pCA350.
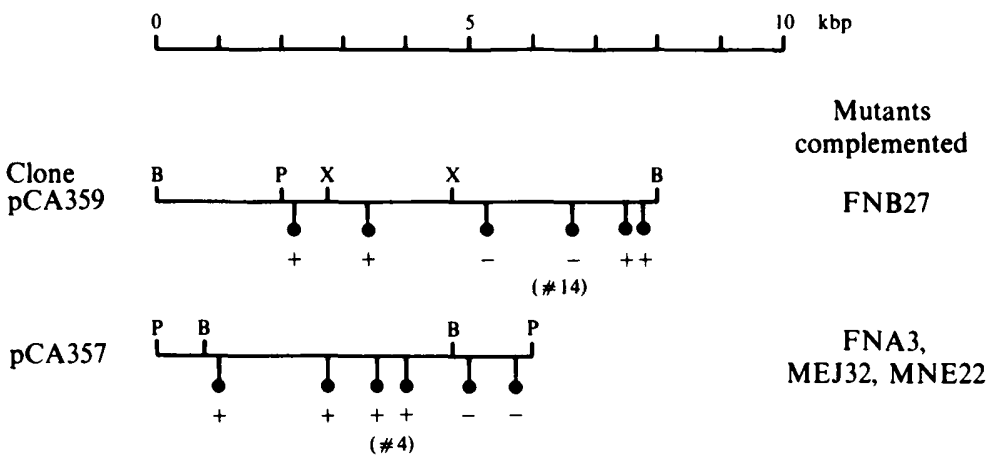

Fig. 3. Subclones of pCA350 that complement $\mathrm{Moh}^{-}$mutants. B, BamHI; P, PstI; X, XhoI. ๑, Tn5 insertions ( + indicates complementation was not affected).

MC44, MA47 and FNA3 was achieved at frequencies of $2-5 \times 10^{-3}$ per $\mathrm{Tc}^{\mathrm{r}}$ transconjugant. Several attempts at complementing strain MEH19 were unsuccessful under conditions that should have identified complementation at a frequency of $10^{-6}$ per $\mathrm{Tc}^{r}$ transconjugant. Either the complementing DNA was not present in sufficient amounts in the clone bank or MEH19 cannot be complemented 'in trans'. The same clone bank has been used successfully to complement a variety of Xanthobacter H4-14 mutants (Lehmicke \& Lidstrom, 1985; C. A. Weaver \& M. E. Lidstrom, unpublished data).

Restriction and subcloning analysis of the complementing fragments placed the seven mutants in five complementation groups. MA47 was complemented by pCA50, which contained a $32 \mathrm{kbp}$ fragment (Fig. 2). Subcloning and deletion analysis showed that the complementing activity of pCA50 toward MA47 resided in an $18 \mathrm{kbp}$ HindIII-BamHI fragment.

MC44 was complemented by pCA100, which contained a $26 \mathrm{kbp}$ fragment. The smallest DNA fragment subcloned from pCA 100 that complemented MC44 was the $5 \mathrm{kbp}$ Pst I fragment indicated in Fig. 2. Both orientations of this fragment in the vector pRK404 were capable of complementing MC44. DNA fragments extending from the left-most HindIII site to either the BamHI site at coordinate 11 or to a ClaI site at coordinate 9 were unable to complement MC44. The $10 \mathrm{kbp}$ BamHI-HindIII fragment (coordinates 11-21) also failed to complement. These findings suggest that the sequences required for complementation of MC44 are located within the Pstl fragment noted in Fig. 2, extending rightward from the internal BamHI site.

One clone containing a $22 \mathrm{kbp}$ fragment (pC350) complemented four mutants (FNB27, FNA3, MEJ32 and MNE22). Subcloning revealed that one region of pCA350 complemented FNB27, while a second region complemented the other three mutants (Fig. 3). FNB27 was complemented by an $8 \mathrm{kbp} \mathrm{BamHI}$ fragment (pCA359; Fig. 3). 
Table 2. Substrate utilization among Xanthobacter H4-14 $\mathrm{Moh}^{-}$mutants

\begin{tabular}{|c|c|c|c|c|c|c|c|c|}
\hline \multirow[b]{2}{*}{ Class } & \multirow[b]{2}{*}{$\begin{array}{l}\text { Complementing } \\
\text { clone }\end{array}$} & \multirow[b]{2}{*}{ Isolate } & \multirow[b]{2}{*}{ Mutagent } & \multicolumn{5}{|c|}{ Growth on:* } \\
\hline & & & & methanol & ethanol & formate & $\begin{array}{c}\text { formate } \\
+ \\
\text { methanol }\end{array}$ & $\begin{array}{c}\text { citrate } \\
+ \\
\text { methanol }\end{array}$ \\
\hline $\begin{array}{l}\text { Wild- } \\
\text { type }\end{array}$ & & $\begin{array}{l}\text { Xanthobacter } \\
\text { H4-14 str }\end{array}$ & - & +++ & +++ & + & +++ & +++ \\
\hline I & pCA359 & FNB27 & NA & - & - & + & + & ND \\
\hline II & pCA100 & MC44 & NA & - & +++ & + & + & ND \\
\hline III & pCA50 & MA47 & NA & - & - & + & +++ & ND \\
\hline IV & None & MEH19 & EMS & - & +++ & + & +++ & ND \\
\hline V & pCA357 & FNA3 & NA & - & +++ & + & - & - \\
\hline & & MEJ32 & EMS & - & +++ & + & - & - \\
\hline & & MNE22 & NA & - & +++ & + & $+1-$ & $+1-$ \\
\hline
\end{tabular}

* Methanol and ethanol, $0 \cdot 15 \%$; formate and citrate (sodium salts), $0 \cdot 1 \% .+++, 100-150$ Klett units;,$+ 20-$ 30 Klett units; $+/-$, occasional growth.

$\dagger$ EMS, ethylmethane sulphonate; NA, nitrous acid.

ND, Not determined.

Further analysis of pCA359 showed that the larger PstI-BamHI fragment was sufficient for complementation but that deletion of an internal $2 \mathrm{kbp} X$ hoI fragment removed complementing activity. Mutagenesis with transposon $\operatorname{Tn} 5$ located the complementing sequences to the right of the XhoI fragment (Fig. 3). Therefore, the complementing DNA must span the region from Tn5 insert 14 leftward into the $X$ hoI fragment.

The mutants FNA3, MEJ32 and MNE22 were complemented by a $6.5 \mathrm{kbp}$ Pst I fragment (pCA357). The $4 \mathrm{kbp}$ internal BamHI fragment did not complement these mutants. Mutagenesis of pCA357 with Tn5 indicated that the right-most region of pCA357 was responsible for complementation. A $2.5 \mathrm{kbp}$ fragment generated from pCA357:: Tn5-4 consisting of DNA from the PstI site in the inverted repeat of Tn5 (Jorgensen et al., 1979) to the right-hand PstI site of the cloned DNA complemented fully all three mutants in either orientation.

\section{Phenotypic characterization of the Moh- mutants}

All seven $\mathrm{Moh}^{-}$mutants were characterized according to their pattern of substrate utilization (Table 2). All of these mutants were capable of growth on formate, suggesting that they were defective in functions specific to MeDH or FADH. Growth on ethanol was also tested since previous work has shown that ethanol oxidation in this strain is catalysed by the MeDH (Weaver \& Lidstrom, 1985). Each mutant was further characterized by its MeDH and FADH activities under inducing and non-inducing conditions (Table 3, Fig. 4). It should be noted that with the exception of mutant FNA3, the FADH activity under inducing conditions closely followed the MeDH activity. This correlation may be due to coregulation between the two activities or to secondary effects. Each $\mathrm{Moh}^{-}$complementation class showed different phenotypic characteristics, consistent with the genetic complementation data.

Class I. The class I mutant FNB27 was defective in a step common to methanol and ethanol metabolism. It contained little or no MeDH activity and although normal levels of FADH activity were found in citrate-grown cells, methanol-induced cells showed low activity. Other work in this laboratory has shown that Methylobacterium AMl, a facultative serine-pathway methylotroph, contains 10 distinct Mox genes, which include structural genes for the MeDH and the cytochrome $c_{\mathrm{L}}$, genes involved in association of the cofactor (pyrroloquinoline quinone) with the $\mathrm{MeDH}$ apoprotein, a gene involved in $\mathrm{MeDH}$ and cytochrome $c$ processing, and regulatory genes (Nunn \& Lidstrom, 1986a, $b$ ). It is not known how many of these functions are present in the Xanthobacter H4-14 Mox system. None of the recombinant clones containing Methylobacterium AM1 Mox genes was capable of complementing mutant FNB27, and an internal openreading-frame fragment of the Methylobacterium AM1 MeDH structural gene did not show 


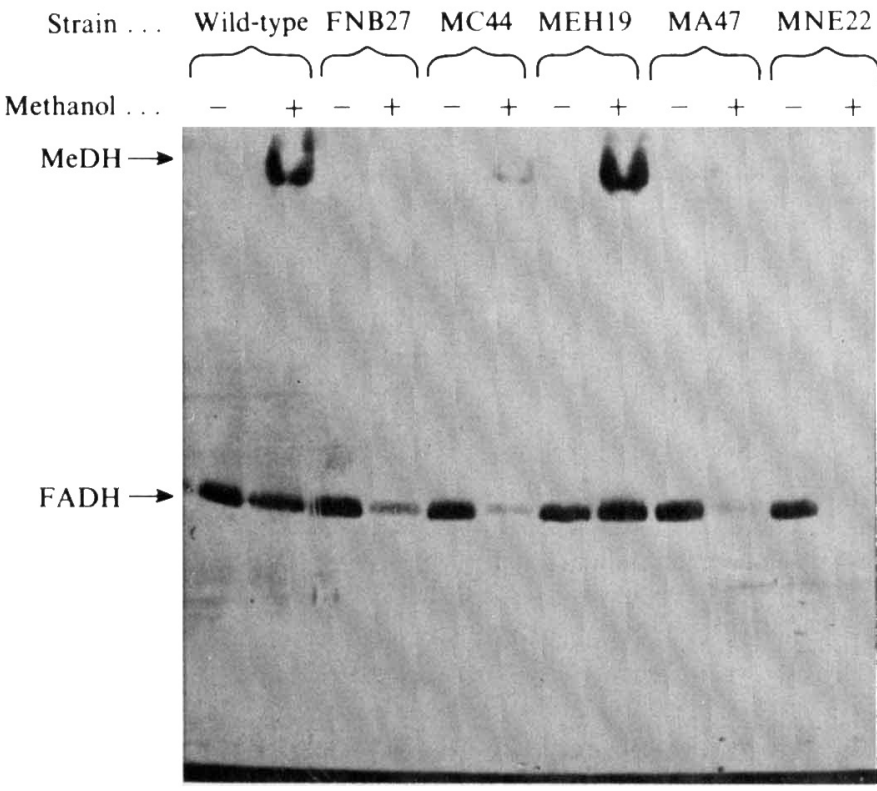

(a)
Wild-type FNA3 MEJ32
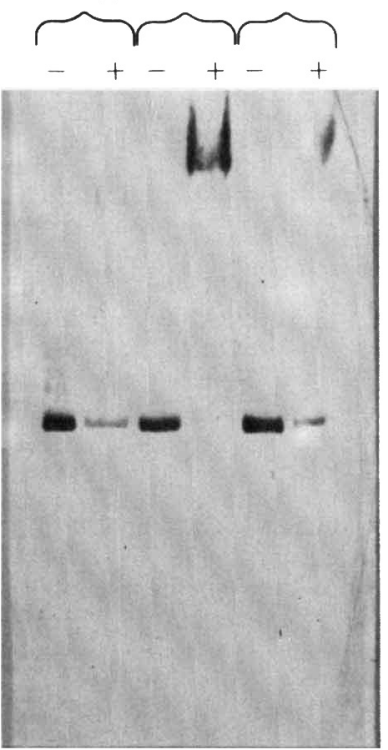

(b)

Fig. 4. FADH activities in Xanthobacter H4-14 $\mathrm{Moh}^{-}$mutants. (a) Strains grown on limiting citrate $(0.035 \%)$ with $(+)$ or without $(-)$ methanol $(0.15 \%)$. Cultures were prepared for FADH assay as described in Methods. (b) Strains grown on citrate $(0.1 \%)$ and then either harvested directly $(-)$, or harvested, washed and diluted twofold into minimal medium with methanol $(0.15 \%)$ for $24 \mathrm{~h}$ before assay $(+)$. The slower-migrating band corresponds to $\mathrm{MeDH}$, while the faster-migrating band corresponds to the FADH. MeDH has activity with formaldehyde but is not the physiologically significant FADH (Weaver \& Lidstrom, 1985).

\section{Table 3. MeDH activities in $\mathrm{Moh}^{-}$mutants}

For mutants FNB27, MC44, MA47, MEH19 and MNE22, MeDH was induced by growing cells on limiting citrate $(0.035 \%, w / v)$ in the presence of methanol $(0.15 \%, v / v)$. For the two more methanolsensitive mutants (FNA3 and MEJ32) MeDH was induced by growing cells to early stationary phase on $0.1 \%$ citrate, harvesting, washing and diluting two-fold into minimal medium with methanol $(0.15 \%)$ for $25 \mathrm{~h}$, or by growing cells on formate. All assays were done in duplicate or triplicate and agreed within $\pm 15 \%$.

\begin{tabular}{|c|c|c|c|c|}
\hline \multirow[b]{2}{*}{ Condition } & \multirow[b]{2}{*}{ Class } & \multirow[b]{2}{*}{ Strain } & \multicolumn{2}{|c|}{$\begin{array}{c}\text { MeDH activity } \\
{\left[\mathrm{nmol} \min ^{-1}(\text { mg protein })^{-1}\right]}\end{array}$} \\
\hline & & & $0.035 \%$ Citrate & $\begin{array}{l}0.035 \% \text { Citrate }+ \\
0.15 \% \text { methanol }\end{array}$ \\
\hline \multirow[t]{2}{*}{ I } & $\begin{array}{c}\text { Wild-type } \\
\text { I } \\
\text { II } \\
\text { III } \\
\text { IV } \\
\text { V }\end{array}$ & $\begin{array}{l}\text { H4-14 str } \\
\text { FNB27 } \\
\text { MC44 } \\
\text { MA47 } \\
\text { MEH19 } \\
\text { MNE22 }\end{array}$ & $\begin{array}{l}0.5 \\
0 \\
1 \cdot 1 \\
1 \cdot 1 \\
1.4 \\
2 \cdot 3\end{array}$ & $\begin{array}{r}51 \cdot 7 \\
0 \cdot 8 \\
5 \cdot 6 \\
8 \cdot 0 \\
37 \cdot 0 \\
46 \cdot 6\end{array}$ \\
\hline & & & $0.1 \%$ Citrate & $0.1 \%$ Formate \\
\hline \multirow[t]{2}{*}{ II } & $\begin{array}{c}\text { Wild-type } \\
\mathbf{V} \\
\mathbf{V}\end{array}$ & $\begin{array}{l}\text { H4-14 str } \\
\text { FNA3 } \\
\text { MEJ32 }\end{array}$ & $\begin{array}{r}1.0 \\
27 \cdot 1 \\
12.0\end{array}$ & $\begin{array}{r}25.0 \\
138.0 \\
25.4\end{array}$ \\
\hline & & & $0.1 \%$ Citrate & $\begin{array}{l}0.1 \% \text { Citrate }+ \\
0.1 \% \text { methanol }\end{array}$ \\
\hline III & Wild-type & $\begin{array}{l}\text { H4-14 } \text { str }^{r} \\
\text { FNA3 } \\
\text { MEJ32 }\end{array}$ & $\begin{array}{l}0 \\
7 \cdot 3 \\
6 \cdot 5\end{array}$ & $\begin{array}{r}1 \cdot 0 \\
35 \cdot 9 \\
12 \cdot 1\end{array}$ \\
\hline
\end{tabular}


hybridization to any of the clones under a stringency allowing $25 \%$ base pair mismatch (E. Minnich \& M. E. Lidstrom, unpublished data).

Class II. The class II mutant MC44 was able to grow on formate and ethanol but not methanol suggesting impairment in formaldehyde oxidation. However, MC44 contained normal levels of FADH activity in citrate-grown cells (Fig. 4), while under inducing conditions $\mathrm{MeDH}$ and FADH activities were both low. Considering that these two activities appear to be coregulated in the presence of methanol, the low $\mathrm{MeDH}$ activities may simply reflect a response to low FADH activities. Therefore, MC44 may be defective in a component of FADH not necessary for the cell-free assay (e.g. an electron transport component). Alternatively, we cannot rule out the possibility that this FADH is not the physiologically significant activity, and if so, MC44 may be deficient in an unidentified FADH. Whole cells of MC44 grown under inducing conditions oxidize formaldehyde at low rates. However, since these cells contain low levels of MeDH activity, it is not possible to determine whether this oxidation is due to MeDH or FADH.

Class III. Strain MA47 was unable to grow on methanol or ethanol suggesting that it is defective in the Mox system. However, MA47 contained low but significant levels of MeDH under inducing conditions and grew normally on methanol in the presence of formate (Tables 2 and 3). This suggests that MA47 lacks a regulatory signal for the Mox system that is normally present during growth on methanol or ethanol but which can also be supplied by growth on formate. Formate-grown wild-type cells do contain partially induced $\mathrm{MeDH}$ levels (Table 3).

Class IV. Strain MEH19 had growth characteristics similar to MA47, except that it grew normally on ethanol. This suggested a defect in the regulation of formaldehyde oxidation that was corrected by growth on formate. However, MeDH and FADH activities were normal in cell-free extracts. The only abnormal characteristic noted was the overproduction of a polypeptide of approximately $24 \mathrm{kDa}$ in methanol-induced cells (data not shown). This $24 \mathrm{kDa}$ polypeptide was not detected in the wild-type strain or in other mutants, and its role is unknown. The apparently normal growth on methanol in the presence of formate observed in both class III and IV mutants suggests a generalized derepression may occur during growth on formate, a poor carbon and energy source. Derepression of genes at low growth rates has been shown to occur in a variety of bacteria (Harder \& Dijkhuizen, 1983).

Class $V$. The mutants in class $\mathrm{V}$ can be described as methanol-sensitive: they are unable to grow on any substrate in the presence of methanol although they grow normally in the absence of methanol. Strain MNE22 showed a leaky phenotype when compared with FNA3 and MEJ32 in that occasionally it grew poorly on formate or citrate in the presence of methanol. Because of this unusual phenotype, these mutants were studied in greater detail.

The data in Table 3 and Fig. 4 offer a possible explanation for methanol sensitivity, especially in the case of FNA3. In the presence of methanol, MeDH activities were induced, sometimes to an abnormally high level, from a partially constitutive level in the absence of methanol. FADH activities remained low or undetectable. It seems likely that in these strains high levels of MeDH convert methanol to formaldehyde in amounts too great to be accommodated by FADH activities. To test this hypothesis, citrate-grown cells of wild-type and FNA3 were pulsed with methanol, and tested for formaldehyde accumulation. Citrate-grown cells of wild-type contained no detectable whole-cell methanol oxidase activity and did not accumulate formaldehyde. FNA3 cells produced formaldehyde from methanol at a linear rate that paralleled the whole-cell methanol oxidase activity.

These data suggest that strains FNA3, MEJ32 and MNE22 contain a regulatory defect that allows both partial constitutivity and hyper-inducibility for $\mathrm{MeDH}$. A dual control mechanism with an altered negative regulatory element in the presence of a functional activator would account for this phenotype. Consistent with this hypothesis is the observation that strains FNA3, MEJ32 and MNE22 contained constitutive or hyper-inducible levels of the $22 \mathrm{kDa}$ polypeptide (Fig. 5) that was previously identified as methanol-inducible (Weaver \& Lidstrom, 1985). Moreover, formate-grown FNA3 produced higher levels of the methanol-inducible $10 \mathrm{kDa}$ polypeptide in amounts that parallel MeDH (Fig. 5).

Regulation in mutant FNA3 was studied in more detail. Table 4 and Fig. 6 show biochemical analyses of mutant FNA3 and its complemented derivatives. Complementation restored wildtype regulation of $\mathrm{MeDH}$ activity, reducing the partially constitutive activity to an undetectable 

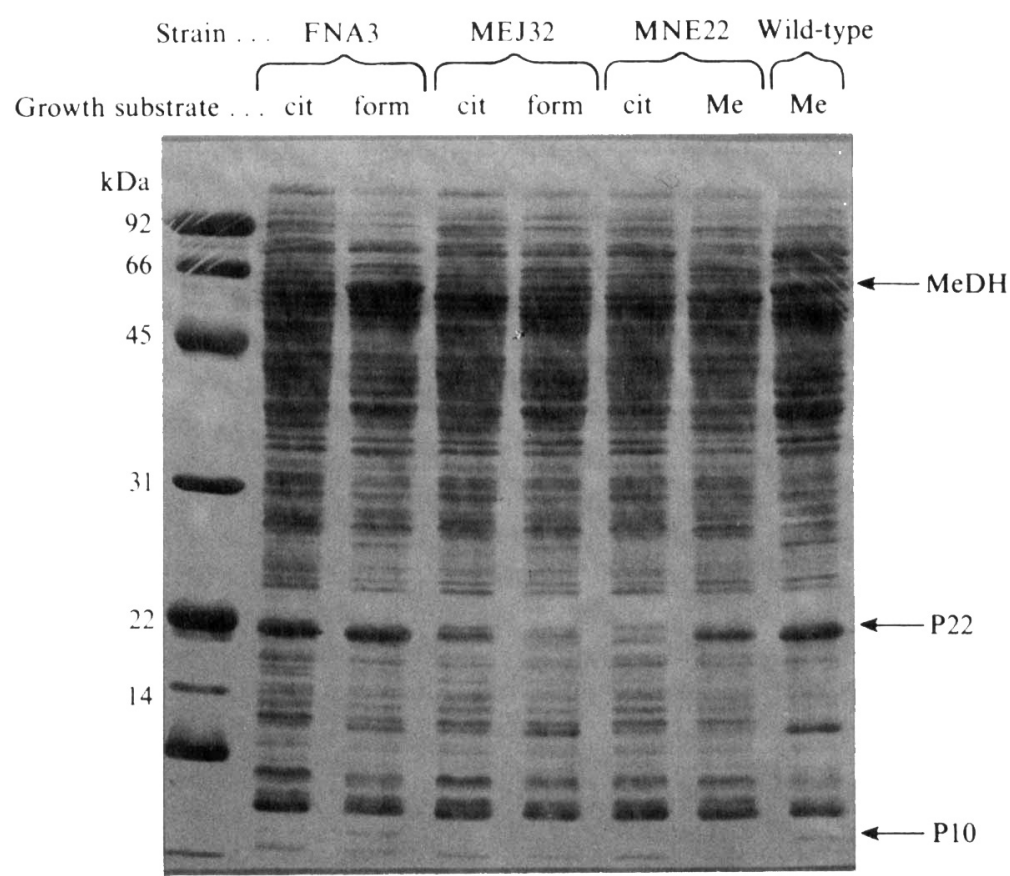

Fig. 5. Polypeptides in class V Moh- mutants. Crude extracts from conditions I and II in Table 3 were analysed by SDS-PAGE. cit, Citrate; form, formate; Me, methanol.

Table 4. MeDH activities in FNA3 and its complemented derivatives

All strains were grown on $0 \cdot 1 \%$ citrate. All assays were done in duplicate and agreed within $\pm 15 \%$.

$\begin{array}{ccc}\text { Strain } & \text { Plasmid } & \begin{array}{c}\text { MeDH activity } \\ \text { [nmol } \text { min }^{-1} \text { (mg protein) }\end{array} \\ \text { H4-14 } \text { str }^{-1} & \text { pCA357 } & 0.4 \\ & \text { pCA359 } & 2 \cdot 3 \\ \text { FNA3 } & \text { pRK404 } & 19 \cdot 9 \\ & \text { pCA357 } & 0 \\ & \text { pCA359 } & 20.1\end{array}$

level and preventing over-expression of the $22 \mathrm{kDa}$ methanol-inducible polypeptide. Since this repression was evident in the complete absence of added $C_{1}$ compounds, it suggests that pCA357 encodes a repressor activity that affects expression of $\mathrm{MeDH}$ as well as the $22 \mathrm{kDa}$ polypeptide. The $10 \mathrm{kDa}$ polypeptide was not detectable in the FNA3 extracts.

These results suggest that in Xanthobacter H4-14 MeDH activity and certain related dissimilatory functions are regulated by a repressor mechanism that may be modulated by an activator mechanism. Methanol oxidation in Xanthobacter H4-14 also appears to be regulated by a catabolite-repression-type mechanism, as is common in facultative methylotrophs (O'Connor, 1981; Weaver \& Lidstrom, 1985). Only low amounts of MeDH activity were detected when a good substrate (e.g. citrate) was present in addition to methanol, and intermediate amounts were seen with poorer substrates (e.g. formate; see Table 3 and Fig. 2). This additional level of regulation may explain why mutants defective in the proposed repressor (FNA3, MEJ32, MNE22) did not show fully constitutive MeDH activity. Unfortunately it was not possible in this experiment to determine whether the methanol-inducible $10 \mathrm{kDa}$ polypeptide was under the control of the putative repressor since low, partially constitutive expression of this small polypeptide would not be detected. However, parallel expression of the $10 \mathrm{kDa}$ polypeptide and 


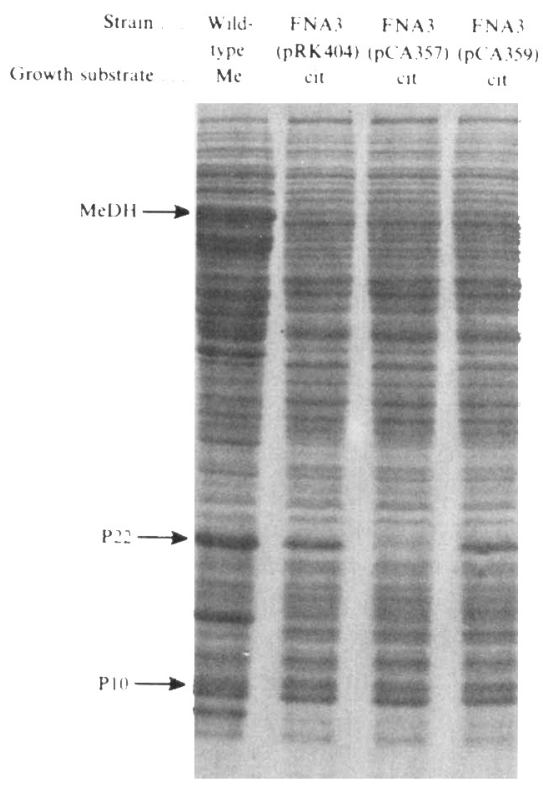

Fig. 6. Polypeptides in FNA3 and its complemented derivative. Crude extracts from the experiment described in Table 4 were analysed by SDS-PAGE. cit, Citrate; Me, methanol.

MeDH in FNA3 grown on citrate and formate (Fig. 5) suggests that they may be coordinately controlled by the proposed repressor.

The regulation of formaldehyde oxidation is more complex and because the biochemistry is not clear, it is not yet possible to draw conclusions. The data presented here add further suggestive evidence that the putative $C_{1}$ FADH detected on activity gels may be the physiologically significant activity. Because FADH activity shows high levels of activity with longer chain aldehydes (Weaver \& Lidstrom, 1985), and is prominent in citrate-grown cells (Fig. 4), this enzyme may be necessary for growth on multi-carbon compounds as well as $C_{1}$ compounds. However, the observations that this activity is under methanol-dependent control and that the class $\mathrm{V}$ mutants exhibit an extreme degree of this control (Fig. 5), argue that this putative FADH is responsible for formaldehyde oxidation during growth on methanol. It seems likely from our data that $\mathrm{MeDH}$ activity may directly regulate the FADH. The phenotype of the class $\mathrm{V}$ mutants suggests that this regulation can be uncoupled, and therefore multiple regulatory elements must be involved in the regulation of methanol dissimilation. Formaldehyde oxidation is uncertain in other methylotrophs as well. In another autotrophic methylotroph, Paracoccus denitrificans, data obtained from work on mutants suggest that a dye-linked FADH with low activities in cell-free extracts may be the physiologically significant enzyme, rather than the NAD+-linked FADH that is also present in that strain (Harms et al., 1985). It is not known if this FADH is similar to the enzyme found in Xanthobacter H4-14.

\section{CONCLUSIONS}

The combination of genetic and phenotypic data presented here suggest that the class I and III mutants are defective in steps associated with methanol oxidation, the class II and IV mutants are defective in steps involved with formaldehyde oxidation, and the class $\mathrm{V}$ mutants are defective in a $\mathrm{C}_{1}$ repressor. The genes defective in the class II and III mutants are not closely linked to each other or to the class I and V mutants. However, the genes defective in the class I and $\mathrm{V}$ mutants were found on the same complementing DNA fragment, separated by approximately $10 \mathrm{kbp}$ of DNA. It is possible that the intervening sequences contain other genes involved in methanol dissimilation. Further studies will be necessary to determine whether 
other $\mathrm{C}_{1}$ genes are present on this DNA fragment. That the other Moh- mutants were complemented by different DNA sequences speaks against the existence of a complete or contiguous methanol dissimilation operon. The genes responsible for $\mathrm{CO}_{2}$ fixation and $\mathrm{H}_{2}$ oxidation in Xanthobacter H4-14 reside on different DNA fragments, separated by at least 10$20 \mathrm{kbp}$ (Lehmicke \& Lidstrom, 1985), and therefore these autotrophy genes are not linked to the Moh genes we have reported here.

The dual control system suggested by our data for methanol dissimilation in Xanthobacter H414 is in contrast to the regulation observed in Methylobacterium AM1. In this facultative serinepathway methylotroph, the Mox system appears to be under positive control (Nunn \& Lidstrom, $1986 a, b)$. Therefore, although the Mox system is similar in biochemical terms, the regulatory system appears to have evolved quite differently in these two different methylotrophs. Apparent regulatory mutants of $P$. denitrificans, have been isolated, but their genetic basis is unknown (Harms et al., 1985). A dual regulatory mechanism for methanol dehydrogenase has been suggested in this organism, based on physiological data (de Vries et al., 1986). A recent report on an obligate ribulose-monophosphate-pathway methanol-utilizer (Methylophilus methylotrophus) shows that the methanol oxidation system is subject to significant regulation, depending upon the growth conditions (Greenwood \& Jones, 1986). It will be of interest to compare the regulatory mechanisms of methanol dissimilation in these different classes of methylotrophs.

This work was supported by a grant from the Public Health Service (no. 5 RO1 GM27766).

\section{REFERENCES}

Allen, L. N., Olstein, A. D., Haber, C. A. \& HANSON, R. S. (1984). Genetic and biochemical studies of representative type II methylotrophic bacteria. In Microbial Growth on $C_{1}$ Compounds, pp. 236-243. Edited by R. L. Crawford \& R. S. Hanson. Washington, DC: American Society for Microbiology.

ANTHONY, C. (1982). The Biochemistry of Methylotrophs, pp. 1-57. London: Academic Press.

Backman, K., Prashen, M. \& Gilbert, W. (1976). Construction of plasmids carrying the $\mathrm{cl}$ gene of bacteriophage lambda. Proceedings of the National Academy of Sciences of the United States of America 73, 4175-4178.

BEARDMORE-Gray, M., O'KeEFFE, D. T. \& ANTHONY, C. (1982). The autoreducible cytochromes $c$ of the methylotrophs Methylophilus methylotrophus and Pseudomonas AM1. Biochemical Journal 207, 161165.

Delucia, P. \& CaIRns, J. (1969). Isolation of an E. coli strain with a mutation affecting DNA polymerase. Nature, London 224, 1164-1167.

Ditta, G., Schmidhauser, T., Yakobson, E., LU, P., Liang, X., Finely, D., Guiney, D. \& Helinski, D. (1985). Plasmids related to the broad host range vector pRK290, useful for gene cloning and monitoring gene expression. Plasmid 13, 149-153.

FIGURSKI, D. \& HeLINSKI, D. R. (1979). Replication of an origin-containing derivative of the plasmid $R K 2$ dependent on a plasmid function provided in trans. Proceedings of the National Academy of Sciences of the United States of America 76, 1648-1652.

Fulton, G. F., NunN, D. N. \& Lidstrom, M. E. (1984). Molecular cloning of a malyl coenzyme A lyase gene from Pseudomonas sp. strain AM1, a facultative methylotroph. Journal of Bacteriology 160, 718-723.
Greenwood, J. A. \& Jones, C. W. (1986). Environmental regulation of the methanol oxidase system of Methylophilus methylotrophus. Journal of General Microbiology 132, 1247-1256.

Haber, C. L., Allen, L. N., Zhao, S. \& Hanson, R. S. (1983). Methylotrophic bacteria: biochemical diversity and genetics. Science 221, 1147-1153.

HARDER, W. \& DiJkhuizen, L. (1983). Physiological responses to nutrient limitation. Annual Review of Microbiology 37, 1-24.

harms, N., de Vries, G. E., Maurer, K., Veldkamp, E. \& STOUTHAMER, A. H. (1985). Isolation and partial characterization of Paracoccus denitrificans mutants with defects in the metabolism of onecarbon compounds. Journal of Bacteriology 164, 1064-1070.

Higgins, I. J., Best, D. J. \& Hammond, R. C. (1980). New findings in methane-utilizing bacteria highlight their importance in the biosphere and their commercial potential. Nature, London 286, 561-564.

Holloway, B. W. (1984). Genetics of methylotrophs. In Methylotrophs: Microbiology, Biochemistry and Genetics, pp. 317-352. Edited by C. T. Hou. Cleveland, Ohio: CRC Press.

Johnson, P. A. \& QuaYle, J. R. (1964). Microbial growth on $C_{1}$ compounds. 6. Oxidation of methanol, formaldehyde and formate by methanol-grown Pseudomonas AM1. Biochemical Journal 93, 281290.

JoRgensen, R. A., Rothstein, S. J. \& Reznikoff, W. S. (1979). A restriction enzyme cleavage map of Tn 5 and localization of a region encoding neomycin resistance. Molecular and General Genetics 177, 6572.

Knauf, V. C. \& Nester, E. W. (1982). Wide host range cloning vectors: a cosmid clone bank of Agrobacterium T1 plasmids. Plasmid 8, 45-54. 
LEHMICKE, L. G. \& LIDSTROM, M. E. (1985). Organization of genes necessary for growth of the hydrogen/ methanol autotroph Xanthobacter sp. strain H4-14 on hydrogen and carbon dioxide. Journal of Bacteriology 162, 1244-1249.

LidSTROM-O'CONNOR, M. E., Fulton, G. L. \& WOPAT, A. E. (1983). 'Methylobacterium ethanolicum': a syntrophic association of two methylotrophic bacteria. Journal of General Microbiology 129, 3139-3148.

Maniatis, T., Fritsch, E. \& Sambrook, J. (1982). Molecular Cloning, a Laboratory Manual, pp. 1-545. Cold Spring Harbor, New York: Cold Spring Harbor Laboratory.

MEssing, J. (1979). A multi-purpose cloning system based on the single-stranded DNA bacteriophage M13. Recombinant DNA Technical Bulletin, NIH publication 99,2 , no. 2, 43-48.

MILLER, J. (1972). Experiments in Molecular Genetics. Cold Spring Harbor, New York: Cold Spring Harbor Laboratory.

NASH, T. (1953). The colorimetric estimation of formaldehyde by means of the Hantzsch reaction. Biochemical Journal 55, 416-421.

NunN, D. N. \& Lidstrom, M. E. (1986a). Isolation and complementation analysis of 10 methanol oxidation mutant classes and identification of the methanol dehydrogenase structural gene of Methylobacterium sp. strain AM1. Journal of Bacteriology 166, 581-590.

NUNN, D. N. \& Lidstrom, M. E. (1986b). Phenotypic characterization of 10 methanol oxidation mutant classes in Methylobacterium sp. strain AM1. Journal of Bacteriology 166, 592-598.
O'CONNOR, M. L. (1981). Regulation and genetics in facultative methylotrophic bacteria. In Microbial Growth on $C_{1}$ Compounds, pp. 294-300. Edited by H. Dalton. London: Heyden.

O'KeEFFe, D. T. \& ANThony, C. (1980). The two cytochromes $c$ in the facultative methylotroph Pseudomonas AMI. Biochemical Journal 192, 411419.

Ruvkun, G. B. \& Ausubel, F. (1981). A general method for site-directed mutagenesis in prokaryotes. Nature, London 289, 85-88.

de Vries, G. E., Harms, N. \& Maurer, K. (1986). Regulation of Paracoccus denitrificans methanol dehydrogenase synthesis and enzyme expression. Abstract of the International Symposium on $C_{1}$ Compounds, p. 75. Edited by J. A. Duine \& H. W. van Verseveld. Amsterdam: Free University Press.

WeAVER, C. A. \& LiDstrom, M. E. (1985). Methanol dissimilation in Xanthobacter H4-14: activities, induction and comparison to Pseudomonas AMI and Paracoccus denitrificans. Journal of General Microbiology 131, 2183-2197.

WeAVer, C. A., Redborg, A. H. \& Konisky, J. (1981). Plasmid-determined immunity of Escherichia coli $\mathrm{K}-12$ to colicin Ia is mediated by a plasmid-encoded membrane protein. Journal of Bacteriology 148, 817828.

Windass, J. D., Worsey, M. J., Pioll, E. M., Pioll, D., Barth, P. T., Atherton, K. T., DarT, E. C., Byrom, D., Powell, K. \& Senior, P. J. (1980). Improved conversion of methanol to single-cell protein by Methylophilus methylotrophus. Nature, London 287, 396-401. 